\title{
Encounters with a future past: navigating the shifting urban atmospheres of place
}

\begin{abstract}
There is recent concern about the destabilizing influence of individuals' everyday encounters with managed atmospheres. This paper draws on autoethnographic data, information relating to the physical fabric, and narratives from stakeholders involved with the design and management of the Eastside area of Birmingham, UK, to demonstrate how urban atmospheres are also shaped by shifting temporal dynamics, the area's historical, cultural and regulatory context, and the prior experiences individuals bring to spaces undergoing regeneration. The paper concludes by suggesting that this analysis has much to offer to designers, educators and stakeholders involved with improving the design and management of place.
\end{abstract}

\section{Introduction}

Urban atmospheres are inescapably 'there', as space-filling phenomena that influence individuals' moods, movements and bodily engagements with the environment: but they are a 'fuzzy' concept. They may be fleeting and produced through relations between an array of human and non-human entities, and experienced differently at a collective and individual level (Brighenti and Kärrholm 2018). In the context of the redevelopment of former industrial urban areas, for example, several recent accounts explore the extent to which people's sensory and emotional experiences fall in line with planned efforts to spatialize urban atmospheres based on a set of socio-cultural values that support economic gain and consumerism. However, there is a concern that further empirical work should more closely examine how atmospheres change over space and time because of a range of everyday human and non-human factors; how they relate to the historical, cultural and regulatory context of place; and how a focus on the 'felt' body tends to downplay the importance of individuals' memories and backgrounds in shaping their encounters with spaces undergoing regeneration (Steffansdottir 2018).

In response to these suggestions, therefore, this paper explores how the atmosphere of an area known as Eastside, in Birmingham, UK, has been altered, manipulated and managed, during two decades of public-private efforts to regenerate the area. The following account draws on 
ethnographic data, information about the changing physical fabric, and interviews of stakeholders associated with the design and management of Eastside. We demonstrate how individuals' moods, together with a consideration of the ambient and environmental qualities, can provide those involved in the design and management of place with important insights to shape urban design interventions and guide the process of urban change.

\section{Placing urban atmospheres}

The creation of atmospheres is perhaps more synonymous with art, literature, sporting events, cinema, music and theatre, than in the context of architecture and urban design. Though difficult to define and conceptually vague, some argue that atmospheres are important to urban planning because of how they appear from an interplay between different human and non-human elements, including buildings, sites, landmarks, landscapes and so on. These relations shape individuals' feelings, behaviours and perceptions as they interact with their surroundings (Anderson 2014; Schmitz et al. 2011; Böhme 2016). Studies of urban atmosphere tend to be theoretically dense. But there is some practical advice for those who want to understand more about how the production of planned urban atmospheres engages different affective subjectivities, from the individual and the collective, and from the human to other forms of life (Gandy 2017). The message is straightforward: examine the relationship between official efforts to "territorialize" aesthetic components of the urban fabric (for example, different spaces, structures and land uses), the affective and sensory intensities of everyday experiencing, and how weather conditions, changes in lighting, sounds and smells might "grip" the felt body (Brighenti and Kärrholm 2018, 204-206). There is, therefore, a need for greater sensitivity to the diverse ways in which the built environment is co-constructed. This would then enrich ongoing debates on the spatial qualities of urban design (Stefansdottir 2018); and how to create safe, vibrant, 'green' urban spaces, which encourage well-being and social interaction among different people (Carmona 2018).

These are laudable goals, of course. But there are dangers involved with developing increasingly sophisticated approaches that chart how the spatial impact and extent of engineered urban atmospheres shape individuals' interactions with the urban landscape (Brighenti and Kärrholm 2018). For instance, foregrounding the immediate and sometimesfleeting socio-spatial dimension of the urban experience underplays the impact of the 
historical forces involved in the material production of urban atmospheres. Because the evolution of urban areas is complicated and spread over long periods, the balance between continuity and change produces layered landscapes, both complex and of long and uncertain duration, where atmospheres have 'grown' over time (Relph 2017). However, a recent complaint often levelled at local authorities, architects, planners, developers and other 'urban managers' is that they unsympathetically reconfigure outworn, 'unruly' industrial areas that reflect new and sometimes unsuitable atmospheres of consumption, leisure, tourism and housing (Zukin 2010). In this view, the rich, varied atmospheres associated with workingclass production are being increasingly "themed, scrupulously maintained and highly regulated to avoid sensory and affective ambiguity" (Edensor and Sumartojo 2015, 254). Spacious and ordered public sites, buildings of glass, steel and other non-traditional materials, together with new forms of artificial illumination, replace formerly cluttered, brick and stone-built, dark, uninviting manufacturing works; selected heritage features are sanitised and woven into twenty-first-century sensibilities and global circuits of capital; activities and policies stimulate post-industrial land uses suitable for mainly young, middleclass audiences (Degen 2014, 106-107).

There is also a tendency to interpret urban managers' use of plans, design codes, and other regulatory mechanisms as a straightforward, linear continuation of 'modern' attempts to create a landscape of continuity and internal consistency. In some areas, though, an atmosphere of production continues to play a significant role in shaping everyday activity, even in towns and cities that have undergone a great deal of change over the last two hundred years or so (Wesener 2017). And while it is important to recognize the cosmopolitan, interconnected nature of contemporary urban space, aspects of the urban fabric are remarkably resistant to change and can adapt to economic, social, political and environmental conditions (Jones et al., 2017). As Degen $(2017,143)$ acknowledges, control and discipline are certainly part of global contemporary regeneration strategies, but temporal and experiential dynamics may also destabilize their full implementation, as new policies, spaces and different publics evolve over time. Development may stall because of uncertain political or economic circumstances; while at the micro-scale, differential rates of change exist between streets, plots, buildings and other structures, despite development pressure (Feliciotti et al., 2017). Some sites, even those officially identified as being out of place as they await redevelopment, might support an abundance of fauna and flora; or they may 
provide a range of 'unplanned' practical, productive and consumptive activities (Edensor 2018). Furthermore, land use categories, as defined in national and local legislation, become fuzzy when they are invoked in the 'messiness' of development decisions (PhilippopoulosMihalopoulos 2016). Certain 'off stage' actors - developers, landowners, businesses, employees and others involved in sometimes-protracted development processes (Adams and Tiesdell 2014) may not be unswerving in their support of swift, radical change: they could subvert regulatory processes or significantly modify development proposals. This fuzziness is also enabling, though: it allows planners to limit what are felt to be unsuitable forms of change, manage the needs of different socio-economic groups, protect and enhance urban sites of historical or cultural importance, and promote long-term goals of social, spatial and environmental justice (Hubbard and Prior 2018, 54).

Clearly, solutions to creating sustainable places do not lie solely with comprehensive, technical approaches. Individuals' everyday actions, which, deliberately or otherwise, may destabilize attempts to impose spatial order, are also important. So, too, is the need to recognize how the blurring of sounds, smells and sights could provoke unpredictable affective states in ways that may breach attempts to engineer atmospheres. Nevertheless, there is an under-explored tension between examining more closely the immediacy of individuals' affective, spatial engagements with planned spaces (Brighenti and Kärrholm 2018, 206) and the historical and cultural relevance of place (Gandy 2017). For example, in Norway, Stefansdottir's (2018) study of the different atmospheric characteristics present in inner-city and suburban locations in Stavanger and Oslo recognizes the importance of local memories, cultural influences and social backgrounds (relating to age, class, gender, sexuality and ethnicity) in shaping urban atmospheres (see also Hasse 2016). However, the central focus of Stefansdottir's account is on teasing out residents' views of how historic sites, diverse land uses, green spaces, and different sensory dimensions of urban experience can make a positive contribution to the "feeling of life" (330). If, though, as Stefansdottir $(2018,330)$ suggests, the concept of urban atmosphere acts as a vital way of contextualising "places as totalities", then there are also opportunities to explore the experiences of other actors with memories of living, working and socializing in areas undergoing the profound and potentially traumatic disturbances of large-scale regeneration. This would provide a more rounded perspective of the particular atmospheric qualities of places: of local or shared history, of culture and daily routines; and of the way in which recollections of the physical 
fabric 'haunt' people in unforeseen ways, unexpectedly intruding on mundane concerns and influencing their present-day engagements with urban sites, perhaps over extended periods (Adams and Larkham 2016). And, as the following Birmingham case study demonstrates, a much fuller understanding of urban atmosphere would blend an appreciation of individuals' emotional, multi-sensory encounters and recollections with a grasp of the historical, political and regulatory context.

The paper now briefly sketches out the plans and ambitions for Birmingham's Eastside area, before turning to the role of the historical context in helping to understand urban atmosphere. The paper closes by exploring the experiences that shape the varied and unfolding atmospheres.

\section{Birmingham's Eastside}

Unlike Birmingham's urban core, the Digbeth / Deritend area, lying to the east of the city centre, did not undergo radical physical changes following the end of the Second World War, except for the widening of the main street. However, the city's slum clearance programme of the 1950s altered the area's physical fabric. More recently, the effects of economic recession and industrial decline in the late 1970s and 1980s were felt particularly sharply in Digbeth, where several of the city's metal working, automotive and engineering activities were concentrated (Foster 2005, 179). During the 2000s, the area was rebranded as 'Eastside' and formed part of the City Council's wider entrepreneurial regeneration efforts to reverse the impacts of de-industrialization and decay (Lombardi et al., 2011) (Figure 1).

Figure 1. Birmingham Eastside (source: Edina Digimap, crown copyright and database right 2018). 
Despite the economic downturn of 2007-2008, several large-scale public-private cultural redevelopment initiatives, including the compulsory purchase of large land parcels, have emerged. Although there are criticisms of the architectural, planning and overall sustainability principles, and community impacts, associated with recent developments (Jones 2008; Lombardi et al., 2011), regeneration activity continues. The northern part of Eastside now boasts a 'Learning Quarter', including Birmingham City University's new campus, and Birmingham Metropolitan College. There is an improved stretch of the Digbeth Branch canal, a science museum, new residential developments, and a national-award winning city park - an important leisure and a major cultural destination (Birmingham City Council [BCC] 2015). The arrival of the proposed High Speed Rail 2 (HS2) at the new Curzon Street railway station, due to open in 2026, provides the City Council, landowners and developers with a fresh opportunity to stimulate substantial development in Eastside (BCC 2015).

The southern part of Eastside has a residents' association, a branch of the environmental group Friends of the Earth, many small manufacturing firms, commercial businesses, offices, several privately managed car parks, and pockets of retail and wholesale activity. Arts, food, musical and cultural businesses and events are also located here. The activities and land uses reflect a desire on the part of some actors to promote a creative, 'edgy' atmosphere. Some of the edginess is reflected in recent reports of drug use, burglaries, vehicle crime and vandalism (https://twitter.com/digbethpolice/). The City Council and local police have introduced a Public Space Protection Order (PSPO), designed to prohibit the anti-social behaviour of groups of young people (BCC and West Midlands Police 2014) (Figure 1).

\section{Methods and approaches}

Recent studies that closely attend to individuals' experiences of sights, sounds, smells, temperatures and movements of other bodies that help comprise atmospheres are especially valuable in providing rich accounts of how people experience planned-for spaces. Walking and observing, for example, offers one method in this regard. Although thorny questions remain regarding whether this approach, particularly in busy urban spaces, can ever truly capture the diverse spatial and temporal qualities of individuals' experiences, the value of such walks is that they cover different locations and times across the study area. Hence this study draws on data collected from a series of ethnographical walks and observations of 
Eastside. These allowed researchers to observe and experience the dynamic sensory and affective qualities of the area and gain some understanding of the ways in which a range of human and non-human elements shape individuals experiences as they unfolded over time (cf. Edensor and Sumartojo 2015). Over twenty hours of detailed observations of the Eastside City Park and the wider Digbeth area took place; these recorded people's age, comportment, behaviour, gender, and ethnicity. The walks and observations took place in 2015, 2016 and 2017; they captured the changing activities during the morning, lunchtime and late afternoon / early evening, and the studies took place during weekdays and at weekends. Noise, temperature, and smell data were collected at selected points during the walks.

This research also draws on findings from a series of semi-structured stakeholder interviews. The aim in selecting interviewees was to recruit people with varied backgrounds and perspectives on the Eastside area. Interviews were conducted with a local urban designer, architect and academic, a Project Manager for Birmingham City Council responsible for overseeing the design and maintenance of Eastside City Park, the Chair of the Friends of Eastside City Park group, which oversees care of the park, three students (two males, one female) studying for a postgraduate qualification in Planning Built Environments at Birmingham City University, three long-serving female employees of a local manufacturing company, the current Director of the Impact Hub, Digbeth, and a Heritage Advisor for the Canal and River Trust. Although an interview guide was prepared, these were semistructured interviews, allowing interviewees to talk freely about the topics for discussion. On average, the interviews lasted for around an hour: they were recorded, transcribed and coded. An interpretation scheme guided the analysis of data: this included fifteen detailed questions grouped into themes relating to respondents' views of Eastside's atmospheric qualities, their experiences of the area, and their views on how the atmospheres of Eastside might change as development activity continues. Data from ethnographic fieldwork and interviews were triangulated with the semi-structured stakeholder interviews to ensure validity and consistency.

To supplement this information, this paper also uses data collected from a survey of buildings and land uses. This included recording details of the principal land use, and the type, approximate age, and principal walling material (ie external appearance characteristics) 
of buildings. Secondary sources, including Foster's (2005) Pevsner architectural guide to Birmingham, also provided valuable information regarding the historical profile of the area and of some individual buildings. Land use and building information were then mapped; business rate records also demonstrated the range of businesses located in the area (https://data.birmingham.gov.uk/dataset/business-rates), while details of the type and location of planning approvals secured since 2000 were also mapped.

\section{It comes to life!}

Parts of Eastside have many prominent post-industrial buildings of glass, steel, and concrete that align with a stylized contemporary urban aesthetic. Much recent development activity has focused on the northern and western edges of the area. There are fears that official progrowth ambitions (BCC 2015, 16), and a desire on behalf of the City Council to increase residential, retail and office space in Eastside, could have an adverse impact on the identity and distinctiveness of the wider area (http://www.downtowninbusiness.com/digbeth-vsjewellery-quarter-theyre-winners/). For example, the area has a diverse range of public spaces, historic plots, a mixture of land uses, buildings of different ages, sizes and architectural styles, including several locally and statutorily protected buildings from the late-nineteenth century and early-to-mid-twentieth century. Much of Eastside also falls within two conservation areas (BCC 2009); here brick, stone, terracotta, faience and clay tile detail enrich many buildings. And while the street blocks vary in shape and size, the nineteenth-century grid pattern is still clear in the southern part of the area; hence the physical fabric retains a certain 'structural resilience' (Feliciotti et al. 2017) (Figure 2).

Figure 2. Density of plots within each street block and figure ground plans (number of plots per block divided by block area): (1) in the 1890s; (2) in the1970s; and (3) in the 2010s (source: Edina Digimap, crown copyright and database right 2018).

'Traditional' manufacturing and service-based businesses are also attracted by the area's edge-of-city location, the low rental values, short-term leases attached to workshops and industrial units, and other planning frameworks which have sought to preserve and enhance the character of the area while supporting small-scale cultural growth (Lombardi et al., 2011). Recent official business rate data for 2014 , for example, reveal that $74.6 \%$ (47 out of 
63) of the largest businesses and organizations in Eastside involve traditional manufacturing, wholesale, engineering, and education activities

(https://data.birmingham.gov.uk/dataset/business-rates). Unsurprisingly, therefore, many of the sights, smells and sounds recorded in this part of Eastside were strongly evocative of industrial, working-class, and / or productive activities (Figure 3). Several streets in the south and east of the area contained strong and unpleasant metallurgical and paint odours, the smell of potatoes, fish and chips, bacon and vehicle emissions. The sounds of cars, the clanging of metal bashing activities and the sight of vehicle repair shops tended to permeate these streets.

Figure 3. Sensewalk data of the Eastside area.

For some interviewees, walking through the area brought forward a keen sense of loss, an inevitable reckoning of industrial decline, while some the more neglected parts of Eastside stimulated a strange fear of what could happen to the landscape following a future urban catastrophe. One interviewee, for example, spoke of buddleja sprouting through the chinks in the brickwork of nineteenth-century railway viaducts, the "sunken" or culverted river and the canal embowered in trees and vegetation, and the relative absence of human activity at certain times. This interviewee felt that these combine to ensure that some sites occupy a curious, characterful, place located somewhere between the past, present and future:

This part of the city is interesting in its layering. There is a sunken river, the canals with water and vegetation by the new buildings. Then there is a ground plane, streets, old and new buildings, and then a vertical layer - the viaducts. There are sites of interest, like the underused Curzon Railway Station building. They give the area character almost because of the recent changes. There's a weird connection between the past and the future. It's stuck in a moment, almost abandoned, like in some future zombie apocalypse! (male student 1,33).

It is, of course, arguable that students with an interest in urban planning might (over)emphasize the persistence of the area's 'quirky' physical characteristics and 'edgy' sense of place. Yet there are sites at the northern edges of the area that have also stalled. For instance, in 2010, the then UK government announced that the station at Curzon Street / Fazeley Street should be a terminus for the proposed HS2, creating 'planning blight' until the project was authorized and designs produced (an ongoing process at the time of writing). 
The London and Birmingham Railway terminus at Curzon Street (built in 1838) (Figure 4), lying alongside the proposed terminus of the HS2 line, is nationally recognized as a Grade 1 listed building (first designated in 1952) and features in the Birmingham Curzon HS2 Masterplan area (BCC 2015). However, the principal building, "an austere square block, of fine ashlar" (Foster 2005, 189), together with its adjoining site, and fragments of its boundary walls have evaded sustained attempts to recode them as heritage products (Minnis 2015).

Figure 4. West elevation of Curzon Street Station (left). The base of the Grand Junction Railway screen wall (right) (source: authors).

Market uncertainty following the economic decline of the late 2000s, a retreat of development finance, and the doubt surrounding the impact of the government's power to compulsorily purchase land for the HS2 development, have led to a certain degree of "passivity" (Adams and Tiesdell 2014, 171) or reluctance of businesses and prominent local landowners to bring sites forward for development. Hence there are also large areas of temporary 'green space', cleared sites of 'hardstanding' and areas which support different uses and activities (Figure 5). The pace of change is quickening, though. Landowners are beginning to play an increasingly important part in delivering the wider regeneration ambitions. Nonetheless, this sense of spatial and temporal ambiguity is simultaneously hindering and enabling (cf Edensor 2018). The stalled, 'ruined' spaces help to foment creative, experimental atmospheres, as sites evolve to take on new meanings (Degen 2017, 153)

[Digbeth] is a space for experimentation; that's what drives some of the small businesses down here [and] an odd mix of old buildings encourages [...] a sort of different place" (Director of the Impact Hub, Digbeth).

Parts of Eastside are still old and rundown! It feels the same, really, some parts have just been left to rack and ruin, despite the changes. They could smarten all of it up, but I'm not sure that all modern is good (female employee 1 , her emphasis).

There is a big slab of unused concrete where HS2 will go - a strategic site, yes. But people have been looking at a large blank space of car-parking for years before HS2 comes! Just a large slab of concrete; not consumer, university, retail or park! In a way, the old, run-down, 
forgotten sites are almost needed to inspire some sort of creativity (female student, 27, her emphasis).

Figure 5. Land use, age of building age and building materials (source: Edina Digimap, crown copyright and database right 2018).

\section{Fragile atmospheres}

As with other cities, it is arguable that recent redevelopment initiatives help to control certain 'out-of-place' activities, behaviours and feelings, where the "spatio-visual landscaping" (Degen 2014, 104) of new spaces encourage civic activities that fit more comfortably with a post-industrial atmosphere based on certain aesthetic, economic and cultural principles. For instance, as an important "catalyst for the wider redevelopment of the area" and the expansion of the city core (Project Manager, BCC), the new city park provides a generally "visually appealing, safe, inclusive", pleasurable green space and pedestrian route from the city centre for "students, office workers and children" to enjoy (Patel Taylor 2010, 29). Indeed, most interviewees suggested that the park largely succeeds in inviting individuals to use the "space in different and sometimes unusual ways" (Urban Designer). They talked of its "generally safe and pleasant" atmosphere, "where students feel comfortable to linger during the day" (female student, 27), and of a "clean, smart" place suitable for "younger people and their families" (female employee 2). Council publications, popular representations, visual cues, the design and regulatory codes governing the use of the space, the presence of CCTV cameras, and the powers enshrined in the PSPO, also help to manage the bodily disturbances of certain groups. But while there are official efforts which "set the limits of what is proper" (Brighenti and Kärrholm 2018, 209), those responsible for the management of the space talked of the need to encourage a certain openness to the park:

The skateboarders pose a real risk in terms of health and safety for other people [...] I mean we're talking about something up to 100 skateboarders at any one time on the terraces. But others are frightened to go past the skateboarders because of the speed they travel and how loud they can be $[\ldots]$ We want a park that feels safe, that all people can use and enjoy at all times (Project Manager, BCC). 
We're keen to reduce the incidents with groups, skateboarders, and so on, but it's very difficult to recruit volunteers to help with managing activities around the park, because the people around are either students, [or] people working during the day (Chair of the Friends of Eastside City Park).

Despite efforts to manage incidences of anti-social and illegal activities, there is a spatial and temporal instability to urban atmospheres. During one early morning observation, for example, when the weather was cool and rainy, small numbers of young professionals busily walked through the space from the city core and away from the loud sounds and fuel smells of the commuter traffic moving along the road at the edge of the park (Figure 6). During an afternoon observation in March, in contrast, early spring sunlight bathed the space, and different groups, including skateboarders, were enjoying a welcoming atmosphere (Figure 6). The sunlight cast on the shiny pre-cast concrete slabs (Patel Taylor 2010, 44), the sound of the fountains in the centre of the square, and the occasional scent of sweet-smelling perfume, all contributed to the convivial, relaxing ambience. However, a group of footballers (aged 18-24) occupied a grassed area near a group of young skateboarders (also aged 18-24). Minutes later, though, their activities, behaviour, and auditory and visual practices, for a brief period at least, disrupted the official codes governing the use of the space. An errant football from the group of British Asian males suddenly disturbed the skateboarders' use of space, thus altering the pleasant feeling of that part of the square, leading to the creation of an uneasy atmosphere: the loudness of both groups intensified, creating an uncontrollable sonic atmosphere. The defined spaces of the park became blurred, as their activities and marking of territory broadened to other areas. This affected other park users; a group of young female walkers clutched their bags tightly and altered their walking routes to take account of the noisy and mildly aggressive activities of the two groups.

Figure 6. The changing atmospheres of Eastside City Park.

Artificial lighting can design out incidents of anti-social behaviour and activities that do not conform to visions for the park. However, as Gandy (2017) cautions, some accounts of urban atmosphere tend to conflate light, modernity and capitalist urban expansion that somehow creates uniformly bright spaces of consumption. Clearly, the changing spatial and temporal qualities of urban atmosphere challenge the idea of ever-expanding post-industrial cities of light. Furthermore, individuals' everyday urban experiences also change according to backgrounds of those who encounter changing light patterns, noise levels, the 'hidden', unlit 
spaces, and the physical features of the industrial area. Even though the female students and local employees praised the 'characterful' qualities of the area, some interviewees were also wary of venturing too far into the 'quiet' spaces after dark.

People are frightened simply to walk through the dark areas [...] If you put lots of lighting in the more people will come 'out of hours', so it opens-up options for different events to happen. But some people don't respond well to it, so we have low-lit areas, but that is where anti-social behaviour happens $[\ldots]$ the dark and concealed areas (Project Manager, BCC).

When I've walked through the area, alone, as a young, lone female, the industrial area, it's OK during the day, but at night, it just doesn't feel safe, because its dark, and there's not much going on along the roads off Fazeley Street. And walking along the canal, just an eerie silence as you walk from one end to the other, it's a bit creepy (female student, 27).

I'm just not comfortable. I was up by the new student halls of residence [...] there were young people with graffiti paint and they were 'tagging' the locks. I probably should have told them to stop, but I just couldn't! (Heritage Advisor, Canal and River Trust, female).

Individuals' prior experiences, age and social status are also important considerations (Brighenti and Kärrholm 2018). For example, one local employee spoke of how she has come to accept the "young" ambience of this part of Eastside, though she also felt a little excluded by the land uses and activities taking place there. Although this recollection perhaps reflects an overly sentimental longing for the area's past, she also suggested that older people might visit the northern edges of Eastside, if future plans for the park draw inspiration from earlier city-centre events:

I pass [the park] all the time on my bus ride, I just think how nice it looks. People seem happy, chatting. But we've sort of accepted it and choose not to go there. I remember the different music acts in the old Bull Ring; let's have something like that! Or a Victorian-style market [...] places for old people to sit and enjoy a coffee (female employee 1).

\section{Planning for a future past}

Contemporary urban managers are often criticized for their apparent high-handed approach to marshalling an array of urban policies that bring about new, highly visual, predominantly 
middle-class regeneration projects, and which seek to remove non-conforming land uses and activities once associated with industrial production. But such a view perhaps modulates some of the efforts made by planners to improve the city following the impact of recent economic downturns. Moreover, as development pressure increases, so does the feeling on the part of some involved in the process that the need to facilitate, regulate and control urban change may become more urgent. Nevertheless, statutory and non-statutory instruments, together with local officials' interpretation of legislative and policy frameworks, play a key role in militating against unsuitable development, helping planners to manage the pressures of urban change.

An analysis of planning application data for the period 2000 - 2016 reveals that most applications across the entire area were for minor works, change of use, or other small-scale activity, and most of these were permitted (Figure 7). Of course, there are prominent, largescale, “over-sized and boxy” (Heritage Advisor, Canal and River Trust) 'flagship' projects in the northern part of Eastside. A recently-constructed university building (Figure 8) aligns squarely with official visions of the new Learning Quarter designed to attract young professionals. Nonetheless, the conditions attached to the approved application also reflect the City Council's tailored response to some of the concerns and suggestions raised by different individuals during the application process. In this case, the applicant was required to submit and gain approval of further details relating to how the proposal would enhance the ecology, biodiversity and landscaping of the area, deliver appropriate levels of lighting, provide sufficient cycle facilities, and control unwanted odour or noise pollution. There are repeated concerns over the perceived overly burdensome nature of planning regulation, which, if uncaringly applied, stifle development, while making the decision-making progress increasingly confrontational (Adams and Tiesdell 2014). Nevertheless, as demonstrated in this example, various "spatial remedies" are available to planners, which, when enacted in legislation and invoked in the decision-making process, contribute to broader, long-term environmental, social and economic ambitions (Hubbard and Prior 2018, 60).

Figure 7. Approved planning applications since 2000 (source: Edina Digimap, crown copyright and database right 2018). 
Figure 8. Details taken from the Decision Document for planning application 2015/06112/PA, erection of a part 2-storey and part 6-storey extension to Birmingham City

\section{University Curzon Building}

(source:

https://eplanning.birmingham.gov.uk/Northgate/PlanningExplorer/ApplicationSearch.aspx).

Some interviewees were critical of unsympathetic, sweeping efforts to brush away some of the rich, sensory geographies and "character" (female employee 1) of the area's workingclass landscape. Indeed, they spoke critically of official efforts that tend to suppress unsettling memories of large-scale redevelopment and the removal of unwanted, though functional, land uses, activities, and people associated with the area's fine-grain, small-scale, qualities:

It feels like regeneration is almost like a mythological thing [a] kind of belief that regeneration creates high land prices or higher rent. [The] reason for regeneration is for the big guys rather than the small guys [...] I am not sure where Eastside really comes from! (Director of Digbeth's Impact Hub).

Eastside once had a café and restaurant where the [new] park now is, quite close to Millennium Point [...]. An Italian family running the café were moved out, forcibly, by the compulsory purchase order to make way for the park and, eventually, the other developments. My view of regeneration is that the process should start from understanding the history and work to incorporate the existing resources of an area (Urban Designer).

Again, though, there is an inevitable danger of romanticizing imaginative recollections of the area's industrial legacy. For example, local employees spoke warmly of the economic and social opportunities of being involved in an atmosphere of production:

Female employee 2: Birmingham is based on manufacturing and engineering! But kids are not going into traditional jobs like apprenticeship engineering, plumbing, electricians.

Female employee 3: It was that busy back then, we were together, good times!

Female employee 1: But I'm not sure that there will be jobs unless something changes, some of the industry will not be able stay here. I mean, yes, we would like it to! It is a history, and people know and recognise it. 
But some interviewees commented how the area's 'untameable' cultural and historical traces (Stefansdottir 2018) continue to carry affective, sensory and cognitive charges. These 'records' of the past - a blend of real, perceived and imagined pasts, and one which defies planned efforts to manage atmosphere that are almost 'held' in solution, ready to be precipitated in ways that distort individuals' ordered sense of space and time (Adams and Larkham 2016). One male student, for example, commented on how the peaceful, quiet qualities of the canal, together with the vegetation, boats and water, "transported" him from the immediate spatial and temporal context to a happier time and place:

The streets and land use in the southern edges of Eastside are dirty, rundown, and at times, noisy, smells of smoke, banging of metals and smell of cars. But the canal environment, even near the new buildings and University, [with] boats and nature, transports me to peaceful, happier time and place (male student 2, 26).

All interviewees talked positively of how the creation of walkable, green areas, the different sights, smells and sounds, new buildings and land uses, have succeeded in "cleaning-up" some of the "dirty" parts of Digbeth (female employee 2). Thus, most interviewees recognized how wider cosmopolitan forces shape some of the distinctive atmospheric qualities of the area (Relph 2017). They supported the broad principles underpinning official efforts to "expand beyond the city centre" and regenerate an "old industrial area" (Project Manager, BCC). If anything, they accepted how the incremental, sensitive management of the urban fabric contributes to a continuity, which can support feelings of place attachment (Wesener 2017), while acknowledging that opportunities lie ahead to improve serviceable buildings, and the safety of the public realm. When discussing the potential of HS2, interviewees talked of how the City Council, landowners, businesses and local education providers should embrace new opportunities, albeit perhaps cautiously. Here is a chance, perhaps, to strike an appropriate balance between promoting new, creative land uses, retaining and enhancing small-to-medium scale industrial activities, creating training, employment and delivering affordable housing opportunities:

Although there aren't any 'residents' in the area as such, but [...] businesses, other community groups and local education providers could take more of a role in the management of the park and the wider Digbeth area (Chair of the Friends of Eastside City Park). 
HS2 will increase land values but it is an opportunity for Birmingham. Make the old environment better. [HS2] will be coming directly over the canal, but there is an opportunity for this to stimulate more regeneration of the canal (Heritage Advisor, Canal and River Trust).

People should take the opportunity to promote and build on the area's quirky qualities; its building stock, promote some small industry rather than just creatives, and build on the kind of culture there, rather than just promoting the high-speed connection to London (male student 2, 26).

The landlord of this place [their employer] wants to build residential property on it. [But] you need something to make it more residential but affordable too (female employee 1).

\section{Conclusion}

Understanding how the different atmospheric characteristics of place are shaped by the activities of those inhabiting particular urban sites remains a compelling task for urban designers (cf Steffansdottir 2018). The idea of the urban environment can make a positive contribution to exploring the diverse ways in which humans interact with their environments. This paper may be read as a reaction of sorts against some of the more generalized accounts that discuss how the atmosphere of industrial or former industrial areas have been irrevocably altered because of recent large-scale, sweeping planned change. Clearly, today's cities look and feel very different from their industrial pasts: new uses, activities, designs, requirements and lifestyles have radically transformed the way we experience and value them. However, our work on Eastside suggests that the structural characteristics of urban form, which continue to shape the atmosphere of place, have matured over centuries of gradual adaptation and have managed to adapt to different circumstances. Historical and cultural values are therefore important in shaping urban atmosphere. But so, too, are the motives, decisions and actions taken by other actors that give meaning to place. Hence, while it is important to learn lessons about the more damaging nature of comprehensive regeneration plans, planners, too, have a role to play in managing this change. And, as the urban form data and interviews of this study reveal, the feel of particular streets, squares, buildings, landmarks, flora and fauna are influenced by the motives and actions of other unobservable actors in the development process. 
There is more to do, however. For instance, the interview and ethnographic data reveal that individuals' everyday experiences may align with official efforts to re-package the historic environment and / or create new post-industrial sites but, at other moments and in other spaces, experiences evade planned attempts to manage the environment, provoking unanticipated, affective and sensory responses and imaginative recollections that transcend time and space. In certain places and at certain times, the landscape is frightening, dark, dirty, polluting, noisy and arguably in need of sensitive planned intervention that improves aspects of the public realm. Talking to people about their experiences of living, working, socializing in a particular area helps to reveal how the atmospheric qualities change over time and space but also because of the kind of values and prior experiences people bring to the present-day experience. This conclusion helps soften the view developed in some recent empirical accounts which tends to overplay the importance of capturing the immediacy of individuals' spatial encounters with planned-for urban atmospheres, without giving a fuller consideration of this spatial and temporal ambivalence.

The final broad contribution from this research, therefore, is that ethnographic walks, combined with a careful reading of urban form, together with interviews taken from selected actors in the development process, can give valuable additional theoretical and practical insight into the physical, tangible and intangible aspects to urban atmosphere. This approach is clearly transferrable to other areas and contexts. This is a necessary step, perhaps, to unlocking the potential of an area's intrinsic qualities, thus helping policy-makers to create safe, pleasant, inclusive and sustainable places.

\section{Acknowledgements}

The authors would like to thank all the interviewees for taking the time to participate in this study. Thanks, too, go to Tim Edensor for his valuable comments on an earlier draft. Finally, the authors gratefully appreciate the feedback from Jeremy Whitehand and other members of the Urban Morphology Research Group.

\section{Notes}


${ }^{1}$ Ninety per cent of the 303 individuals recorded during the 2016 observations of the park were pedestrians. Marginally more 'white' people used the park than 'non-white'; most people were male and under thirty years old.

\section{References}

Adams, D. and S. Tiesdell 2014. Shaping Places: Urban Planning, Design and Development. London: Routledge.

Adams, D. and P.J. Larkham 2016. "Walking with the ghosts of the past: Unearthing the value of residents' urban nostalgias." Urban Studies 53 (10): 2004-2022.

Anderson, B. 2014. Encountering Affect: Capacities, Apparatuses, Conditions. Farnham: Ashgate. Birmingham City Council 2009. Digbeth, Deritend and Bordesley High Streets (Digbeth/Deritend) Conservation Area March 2009: Character Appraisal and Supplementary Planning Policies. Birmingham: Birmingham City Council.

Birmingham City Council 2015. Birmingham Curzon HS2: Masterplan for Growth. Birmingham: Birmingham City Council.

Birmingham City Council and West Midlands Police 2014. Public Space Protection Order (PBSO) Eastside Park area, covering Fazeley Street, Park Street, New Canal Street, Curzon Street, Cardigan Street, Jennens Road, Howe Street, Grosvenor Street, Etna Street and Fox Street. Birmingham: Birmingham City Council.

Böhme, G. 2016. The Aesthetics of Atmospheres. London: Routledge.

Brighenti, A. M., and M. Kärrholm 2018. "Atmospheres of retail and the asceticism of civilized consumption." Geographica Helvetica 73: 203-213.

Carmona, M. 2018. "Place value: place quality and its impact on health, social, economic and environmental outcomes." Journal of Urban Design https://doi.org/10.1080/13574809.2018.1472523.

Degen, M. 2014. "The Everyday City of the Senses." In Cities and Social Change: Encounters with Contemporary Urbanism, edited by R. Paddison and E. McCann, 92-113. London: Sage.

Degen, M. 2017. "Urban Regeneration and "Resistance of Place": Foregrounding Time and Experience." Space and Culture 20 (2):141-155.

Edensor, T., and S. Sumartojo 2015. "Designing Atmospheres: Introduction to Special Issue.” Visual Communication 14 (3): 251-265.

Edensor, T. 2018. "Creative engagements with the past: aesthetics and matter in ruined spaces." In G. Heeney. (Ed.), The Post-Industrial Landscape as Site for Creative Practice: Material Memory. Cambridge: Cambridge Scholars Press. 
Feliciotti, A., O. Romice, and S. Porta 2017. "Urban regeneration, masterplans and resilience: the case of Gorbals, Glasgow.” Urban Morphology 21 (1): 1-19.

Foster, A. 2005. Pevsner Architectural Guides: Birmingham. London: Yale University Press.

Gandy, M. 2017. "Urban atmospheres." Cultural Geographies 24 (3): 353-374.

Hasse, J. 2016. "Traffic Architecture.” Elements of Architecture: Assembling Archaeology, Atmosphere and the Performance of Building Spaces 177: 177-194.

Hubbard, P., and J. Prior 2018. "Law, pliability and the multicultural city: Documenting planning law in action." Geographical Journal 184 (1): 53-63.

Jones, P. 2008. "Different but the same? Post_war slum clearance and contemporary regeneration in Birmingham, UK." City 12 (3): 356-371.

Jones, P., A. Isakjee, C. Jam., C. Lorne., and S. Warren 2017. "Urban landscapes and the atmosphere of place: exploring the subjective experience in the study of urban form." Urban Morphology $21(1): 1-12$.

Lombardi, R.D., L. Porter, A. Barber., and C. Rogers 2011. "Conceptualising sustainability in UK urban regeneration: a discursive formation." Urban Studies 48 (2): 273-296.

Minnis, J. 2015. Curzon Street Station, Birmingham: research report series 029-2015. London: Historic England.

Patel Taylor LLP 2010. Eastside City Park: Reserved Matters. London: Patel Taylor LLP. Philippopoulos-Mihalopoulos, A. 2016. "Withdrawing from atmosphere: An ontology of air partitioning and affective engineering." Environment and Planning D: Society and Space 34 (1): $150-167$.

Relph, E. 2017. “A Pragmatic Sense of Place and the Future of Places”. http://www.placeness.com/apragmatic-sense-of-place-and-the-future-of-places/.

Schmitz, H., R. O. Müllan, and J. Slaby. 2011. "Emotions Outside the Box-The New Phenomenology of Feeling and Corporeality." Phenomenology and the Cognitive Sciences 10 (2): 241-259.

Stefansdottir, H. 2018. “The role of urban atmosphere for non-work activity locations.” Journal of Urban Design 23 (3): 319-335.

Wesener, A. 2017. “Adopting 'things of the little': intangible cultural heritage and experiential authenticity of place in the Jewellery Quarter, Birmingham." International Journal of Heritage Studies 23 (2): 141-155.

Zukin, S. 2010. Naked City: The Death and Life of Authentic Urban Places. Oxford: Oxford University Press. 